\title{
Antihypertensive and antioxidant effects of dietary black sesame meal in pre-hypertensive humans
}

\author{
Jatuporn Wichitsranoi ${ }^{1}$, Natthida Weerapreeyakul ${ }^{2}$, Patcharee Boonsiri ${ }^{3}$, Chatri Settasatian ${ }^{4}$, Nongnuch Settasatian ${ }^{5}$, \\ Nantarat Komanasin ${ }^{6}$, Suchart Sirijaichingkul ${ }^{7}$, Yaovalak Teerajetgul ${ }^{5}$, Nuchanart Rangkadilok ${ }^{8}$ and \\ Naruemon Leelayuwat ${ }^{{ }^{*}}$
}

\begin{abstract}
Background: It has been known that hypertension is an independent risk factor for cardiovascular disease (CVD). CVD is the major cause of morbidity and mortality in developed and developing countries. Elevation of blood pressure (BP) increases the adverse effect for cardiovascular outcomes. Prevention of increased BP plays a crucial role in a reduction of those outcomes, leading to a decrease in mortality. Therefore, the purpose of this study was to investigate the effects of dietary black sesame meal on BP and oxidative stress in individuals with prehypertension.

Methods: Twenty-two women and eight men (aged $49.8 \pm 6.6$ years) with prehypertension were randomly divided into two groups, 15 subjects per group. They ingested $2.52 \mathrm{~g}$ black sesame meal capsules or placebo capsules each day for 4 weeks. Blood samples were obtained after overnight fasting for measurement of plasma lipid, malondialdehyde (MDA) and vitamin E levels. Anthropometry, body composition and BP were measured before and after 4-week administration of black sesame meal or a placebo.

Results: The results showed that 4-week administration of black sesame meal significantly decreased systolic BP $(129.3 \pm 6.8$ vs. $121.0 \pm 9.0 \mathrm{mmHg}, P<0.05)$ and MDA level $(1.8 \pm 0.6$ vs. $1.2 \pm 0.6 \mu \mathrm{mol} / \mathrm{L}, P<0.05)$, and increased vitamin E level $(29.4 \pm 6.0$ vs. $38.2 \pm 7.8 \mu \mathrm{mol} / \mathrm{L}, P<0.01)$. In the black sesame meal group, the change in SBP tended to be positively related to the change in MDA ( $R=0.50, P=0.05)$, while the change in DBP was negatively related to the change in vitamin $\mathrm{E}(R=-0.55, P<0.05)$. There were no correlations between changes in $\mathrm{BP}$ and oxidative stress in the control group.

Conclusions: These results suggest the possible antihypertensive effects of black sesame meal on improving antioxidant status and decreasing oxidant stress. These data may imply a beneficial effect of black sesame meal on prevention of CVD.
\end{abstract}

Keywords: blood pressure, oxidative stress, malondialdehyde, sesamin, sesamolin, tocopherol

\section{Background}

Hypertension is an important risk factor for cardiovascular disease (CVD) in developing countries. Elevation of blood pressure (BP) is a risk factor for adverse cardiovascular outcomes, including stroke, myocardial infarction, renal failure and death [1]. Prevention of increased BP

\footnotetext{
* Correspondence: naruemon@kku.ac.th

${ }^{9}$ Department of Physiology, Faculty of Medicine, Khon Kaen University, Khon Kaen 40002, Thailand

Full list of author information is available at the end of the article
}

therefore plays a crucial role in a reduction of those outcomes. Impaired balance between relaxing and contracting factors in the endothelium of blood vessels is an important pathogenic mechanism of hypertension. Increased pro-oxidant and decreased antioxidant activities have been shown to be some of the mechanisms of the pathogenesis of hypertension [2].

It has been reported that sesame seeds can improve oxidative stress due to actions of their contents of vitamin $\mathrm{E}$ and lignans including sesamin, sesamolin and sesamol

\section{Biomed Central}


[3-7]. Thus, sesame is likely to have potential health benefits in relation to CVD by its antihypertensive effects [8-11]. Although many previous studies have shown different effects of vitamin E on BP [12-14], these studies investigated the effect of supplementation of either alphatocopherol alone or mixed with gamma-tocopherol on BP in diabetic [12,13] or hypertensive [14] patients who took antihypertensive drugs. Interactions between alpha-tocopherol and the drug may diminish the antihypertensive effect on BP [15]. Moreover, the dose of vitamin E in those previous studies may have been so high that it caused increased or unchanged effects on BP.

Interestingly, the antihypertensive effect of black sesame (Sesamum indicum Linn.) meal, a product of sesame oil manufacturing, does not seem to have been previously investigated. Positive results may provide additional value to the manufactured product. Since we wanted to examine preventive effects, we performed the research on pre-hypertensive [16] healthy individuals who did not take any medicine; hence the vitamin $\mathrm{E}$ could exercise its antioxidant activity without interference with any antihypertensive drug. Moreover, black sesame meal contains gamma-tocopherol which was reported to be lower in patients with coronary heart disease than control subjects [17]. Taken together with the safety dose of vitamin $E$ in black sesame meal in this study [18], this may reveal an anti-hypertensive effect of black sesame meal.

Based on knowledge of the effects of sesame seed and lignans on oxidative stress, which is one of mechanisms of the pathogenesis of hypertension [2], it was hypothesized that black sesame meal may have an antihypertensive effect in pre-hypertensive humans via improving antioxidant status and decreasing oxidant stress. Therefore, the aim of this study was to investigate the effects of 4-week administration of black sesame meal on BP and oxidative stress in pre-hypertensive humans.

\section{Methods}

\section{Study design}

A double-blind, placebo-controlled investigation was undertaken. Subjects were divided into two groups, with 11 men and 4 women in each group, matched by age, BMI and BP: a black sesame meal group (SG) $(\mathrm{N}=15$, aged $49.3 \pm 7.7$ years), and a placebo group ( $\mathrm{PG})(\mathrm{N}=15$, aged $50.3 \pm 5.6$ years). Subjects and investigators were blinded as to the composition of the black sesame meal and placebo capsules. After being screened by physical and blood examination, all subjects were asked to complete health questionnaires in order to provide health information including cardiovascular risk factors. Subjects were seen on two visits: before and after 4-week administration of either black sesame meal capsules or placebo capsules. During the 4 weeks, subjects were asked to take 6 capsules each time, three times a day, with water after a meal. They were asked to avoid vitamins and other dietary supplements during the administration period. Subjects were instructed not to change their diet and exercise routine throughout the trial. At both visits, after a 12-h fasting period, blood samples were collected to measure blood parameters. Anthropometry (height, weight, and waist and hip circumferences), body composition and BP were also measured.

\section{Subjects}

Thirty middle-aged subjects ( 22 men and 8 women) were recruited from the general population, supported by an annual health checkup program performed at the Faculty of Associated Medical Sciences, Khon Kaen University, during 2008-2009. Subjects had no other diseases except prehypertension as indicated either by systolic blood pressure (SBP) from 120 to $139 \mathrm{mmHg}$ or diastolic BP (DBP) from 80 to $89 \mathrm{mmHg}$ [16]. The patients were not currently taking any medication or dietary supplementation that affected BP. This study was conducted according to the guidelines laid down in the Declaration of Helsinki, and all procedures involving humans were approved by the Ethics Committee of Khon Kaen University (HE 510254). Written and verbal informed consent was obtained from all subjects; verbal consent was witnessed and formally recorded.

\section{Power calculation}

A change in SBP after the ingestion of black sesame meal was used to calculate the sample size of this study [9]. The magnitude of the change in SBP was $5 \mathrm{mmHg}$ for the power calculation. It was decided to require $90 \%$ power at a significance level of 0.05 . Thus, having at least 15 subjects was required to finish this study.

\section{Preparation of black sesame meal}

The black sesame meal was prepared at the Faculty of Pharmaceutical Sciences, Khon Kaen University, Thailand. The sesame seeds were roasted before being pressed. The remaining sesame meal was grounded into powder and mixed with an adsorbent. This process is the same as that used for commercial preparation. Each capsule of black sesame meal was formulated to contain $0.42 \mathrm{~g}$ of black sesame meal. The contents (mean $\pm \mathrm{SD}$ ) of carbohydrate, protein and fiber of the black sesame meal were $46.37 \%$, $21.57 \%$ and $14.12 \%$, respectively. Moreover, sesamin and sesamolin contents were $1.172 \pm 0.002 \mathrm{mg} / \mathrm{g} \mathrm{DW}$ and $0.605 \pm 0.003 \mathrm{mg} / \mathrm{g} \mathrm{DW}$, respectively [19]. Total tocopherol was $105.41 \pm 2.49 \mu \mathrm{g} / \mathrm{g} \mathrm{DW}$, mostly consisting of gamma-tocopherol (102.78 $\pm 2.46 \mu \mathrm{g} / \mathrm{g} \mathrm{DW})$; alpha-tocopherol was not detectable [19]. The placebo capsule contained the same contents, but without any black sesame meal. Both capsules were the same shape and color. 


\section{Measurement of BP}

$\mathrm{BP}(\mathrm{mmHg})$ and heart rate $(\mathrm{HR}, / \mathrm{min})$ were measured in the morning, after a 20-min rest, using an automatic sphygmomanometer (Accurtorr 1A; Datascope, Japan) on the right upper arm while the subject was in a sitting position. Average BP and HR were calculated from three measurements after an almost stable BP seemed to have been reached. SBP and DBP were used to calculate mean arterial pressure (MAP) by the formula: MAP = $\mathrm{DBP}+1 / 3(\mathrm{SBP}-\mathrm{DBP})$.

\section{Measurement of malondialdehyde (MDA)}

A plasma lipid peroxidation marker, MDA, was estimated using thiobarbituric acid, as previously described [20]. In brief, $150 \mu \mathrm{l}$ of plasma was reacted with $125 \mu \mathrm{l} 10 \%$ trichloroacetic acid, $125 \mu \mathrm{l} 5 \mathrm{mM}$ ethylenediaminetetraacetic acid, $125 \mu \mathrm{l} 8 \%$ sodium dodecyl sulfate, and $10 \mu \mathrm{l}$ $0.5 \mu \mathrm{g} / \mathrm{ml}$ butylated hydroxytoluene. After vortexing vigorously for $30 \mathrm{~s}$, the mixture was incubated for $10 \mathrm{~min}$ at room temperature. Then $500 \mu \mathrm{l} 0.6 \%$ thiobarbituric acid was added, and the mixture was heated at $95^{\circ} \mathrm{C}$ for $30 \mathrm{~min}$. After cooling to room temperature, the mixture was centrifuged at 10,000 rpm for $10 \mathrm{~min}$. The absorbance of the supernatant was measured at $532 \mathrm{~nm}$ using a spectrophotometer (Genesys 20, SN: 35 gk 130009; Thermo Fisher Scientific, USA). A standard curve was generated with appropriate concentrations of 1,1,3,3-tetraethoxypropane standard $(0.3-10 \mu \mathrm{mol} / \mathrm{L})$; the plasma MDA concentration was expressed as $\mu \mathrm{mol} / \mathrm{L}$ of plasma.

\section{Measurement of vitamin E}

Serum vitamin E was determined using high performance liquid chromatography (HPLC), according to the method of Thurnham [21], by injection into a reversed-phase C-18 Spherisorb ODS2 column (diameter $5 \mu \mathrm{m}, 4.6 \times 100 \mathrm{~mm}$; Waters, USA). The mobile phase consisted of methanol/ acetonitrile/dichloromethane at a ratio of 4:4:1 with a flow rate of $1 \mathrm{~mL} / \mathrm{min}$. A wavelength $\mathrm{UV}$-visible detector (model 2847, Waters) was set at a wavelength of $292 \mathrm{~nm}$ for the detection of vitamin E. Quantification was based on peak-height measurement, using the Clarity 2.2.0.67 software program, version C22 (DataApex, Czech Republic).

\section{Statistical analysis}

All statistics were generated using Stata statistical software, version 10 (StataCorp, USA). Data were expressed as means $\pm \mathrm{SD}$. Changes in $\mathrm{BP}, \mathrm{MDA}$ and vitamin $\mathrm{E}$ levels between groups were compared by analysis of covariance (ANCOVA), with adjustment for baseline values. The variables under study before and after the administration within groups were compared by Student's paired $t$-test. The relationships between changes in oxidative stress variables and BP were analyzed by Pearson's correlation. Statistical analyses were two-sided. If the statistical probability ( $P$-value) was less than 0.05 , the differences were considered to be statistically significant.

\section{Results}

Baseline characteristics of subjects are shown in Table 1. All subjects were pre-hypertensive individuals. No significant differences in age, anthropometry, body composition, and levels of MDA and vitamin E, SBP, DBP, MAP and HR were found between SG and PG groups.

In the SG group, after 4 weeks of administration of black sesame meal, SBP was significantly decreased when compared with before administration (121.0 \pm 9.0 vs. $129.3 \pm$ $6.8 \mathrm{mmHg}, P<0.05$ ) (Figure 1A). Meanwhile, in the PG group, SBP was slightly decreased after the placebo administration when compared with before administration values $(130.4 \pm 4.8$ vs. $130.6 \pm 9.5 \mathrm{mmHg}, P=0.52)$. The decrease in SBP in the SG group was significantly greater than that in the PG group $(\mathrm{P}<0.05)$ with adjustment for baseline values. There were no apparent side effects induced by black sesame meal throughout the study.

In the SG group, after 4 weeks of administration of black sesame meal, DBP was decreased when compared with before administration $(72.8 \pm 9.8$ vs. $77.0 \pm 7.4$ $\mathrm{mmHg}, P=0.20$ ) (Figure 1B). Meanwhile, in the PG group $(85.9 \pm 12.1$ vs. $80.6 \pm 7.7 \mathrm{mmHg}, P=0.14)$, where the level was higher than before administration.

Table 1 Characteristics and baseline outcome of the subjects at baseline

\begin{tabular}{|c|c|c|c|}
\hline & $\begin{array}{c}P G \\
(n=15)\end{array}$ & $\begin{array}{c}\text { SG } \\
(n=15)\end{array}$ & $P$-value \\
\hline Age (yr) & $50.3 \pm 5.6(39-58)$ & $49.3 \pm 7.7$ (38-59) & 0.70 \\
\hline Height (cm) & $161.4 \pm 5.4(154-171)$ & $159.5 \pm 7.5(150-173)$ & 0.45 \\
\hline BW (kg) & $66.9 \pm 8.7(53.9-78.5)$ & $68.1 \pm 12.1(57.5-92.7)$ & 0.71 \\
\hline BMI $\left(\mathrm{kg} / \mathrm{m}^{2}\right)$ & $25.6 \pm 2.4(21.8-29.1)$ & $26.6 \pm 3.2(22.7-34.3)$ & 0.29 \\
\hline$\% B F$ & $31.5 \pm 4.6(24.7-37.6)$ & $31.6 \pm 3.4(26.7-37.2)$ & 0.92 \\
\hline $\mathrm{FM}(\mathrm{kg})$ & $21.3 \pm 5.1(13.3-28.5)$ & $21.7 \pm 5.2(15.9-32.7)$ & 0.81 \\
\hline FFM (kg) & $45.6 \pm 4.7(37.6-52.9)$ & $46.4 \pm 7.6(37.7-60.9)$ & 0.69 \\
\hline W $(\mathrm{cm})$ & $84.6 \pm 6.9(72-94)$ & $85.8 \pm 9.6(74.5-107)$ & 0.66 \\
\hline $\mathrm{H}(\mathrm{cm})$ & $95.3 \pm 4.9(86-101.5)$ & $96.9 \pm 5.4(88-108)$ & 0.35 \\
\hline W/H ratio & $0.89 \pm 0.1(0.77-0.94)$ & $0.88 \pm 0.1(0.79-1.02)$ & 0.75 \\
\hline MDA $(\mu \mathrm{mol} / \mathrm{L})$ & $1.9 \pm 0.62(0.86-2.78)$ & $1.8 \pm 0.6(1.19-2.81)$ & 0.67 \\
\hline $\begin{array}{l}\text { Vitamin } E \\
(\mu \mathrm{mol} / \mathrm{L})\end{array}$ & $26.5 \pm 5.5(17.2-34.4)$ & $29.4 \pm 6.0(19.1-45.8)$ & 0.18 \\
\hline $\mathrm{SBP}(\mathrm{mmHg})$ & $130.4 \pm 4.8(127-138)$ & $129.3 \pm 6.8(121-137)$ & 0.43 \\
\hline $\mathrm{DBP}(\mathrm{mmHg})$ & $80.6 \pm 7.7(72-99)$ & $77.0 \pm 7.4(65-87)$ & 0.63 \\
\hline MAP $(\mathrm{mmHg})$ & $97.2 \pm 4.7(90.3-108.7)$ & $94.4 \pm 6.1(84.7-103.7)$ & 0.51 \\
\hline $\mathrm{HR}(/ \mathrm{min})$ & $66.8 \pm 7.4(59-85)$ & $68.7 \pm 9.1(53-93)$ & 0.61 \\
\hline
\end{tabular}

Values are expressed as means \pm SD (minimum-maximum).

PG, placebo group; SG, black sesame meal group; BW, body weight; BMI, body mass index; \%BF, percentage of body fat; FM, fat mass; FFM, fat-free mass; $W$, waist circumference; $\mathrm{H}$, hip circumference; $\mathrm{W} / \mathrm{H}$ ratio, waist and hip circumference ratio; MDA, malondialdehyde; SBP, systolic blood pressure; DBP, diastolic blood pressure; MAP, mean arterial pressure; HR, heart rate 


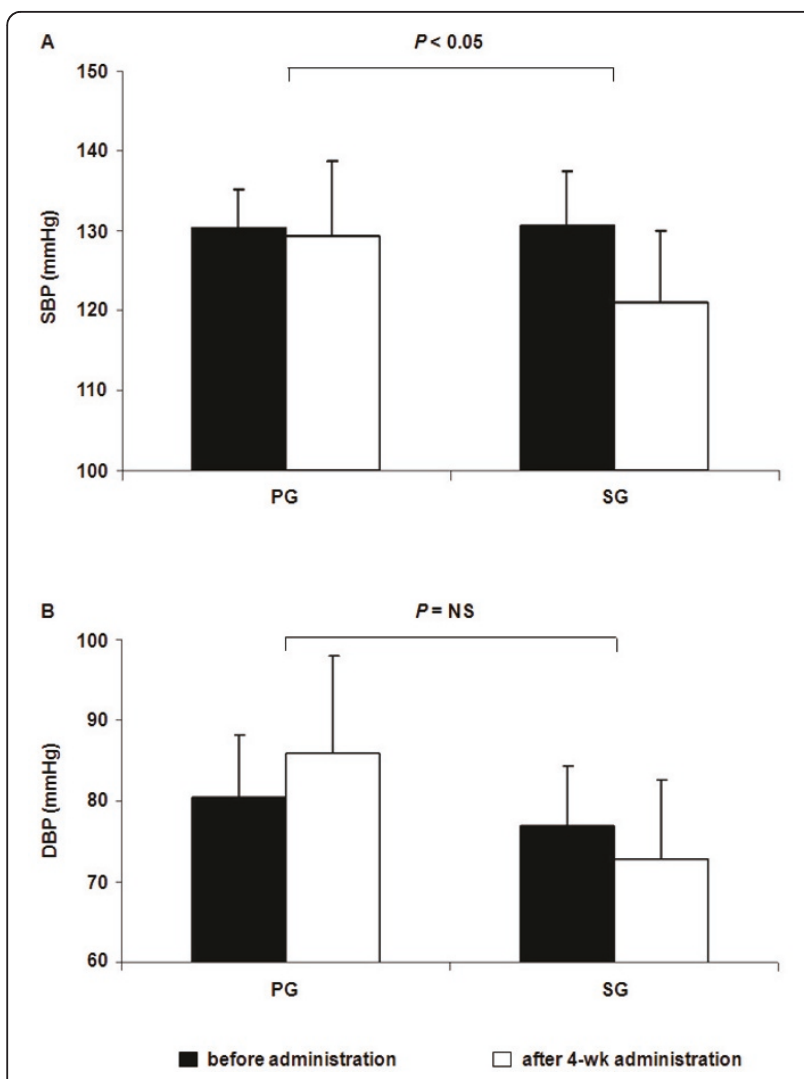

Figure 1 Average levels of SBP (A) and DBP (B) before and after 4-week administration of black sesame meal and a placebo in subjects with prehypertension. Values are expressed as means \pm SD. SBP, systolic blood pressure; DBP, diastolic blood pressure; PG, placebo group; SG, black sesame meal group.
However, the changes in DBP between groups with adjustment for baseline values were not significantly different.

Moreover, there was no significant difference in changes of average HR with adjustment for baseline values in both PG and SG subjects $(66.8 \pm 7.4$ and $68.7 \pm$ $9.1 / \mathrm{min}$ before and $71.2 \pm 11.1$ and $71.4 \pm 6.4 / \mathrm{min}$ after 4-week administration of black sesame meal and placebo, $P=0.76)$.

Plasma MDA concentrations significantly decreased after the 4-week administration of black sesame meal when compared with before administration concentrations $(1.2 \pm 0.6$ vs. $1.8 \pm 0.6 \mu \mathrm{mol} / \mathrm{L}, P<0.05)$. There were no significant differences in MDA concentrations, however, before and after 4-week administration of a placebo (1.8 \pm 0.5 vs. $1.9 \pm 0.6 \mu \mathrm{mol} / \mathrm{L}, P=\mathrm{NS})$. When compared with the PG subjects, the SG subjects had significantly lower plasma MDA concentrations after the 4-week administration with adjustment for baseline values $(1.8 \pm 0.5$ (PG), $1.2 \pm 0.6(\mathrm{SG}) \mu \mathrm{mol} / \mathrm{L}, P<0.05$ ) (Figure 2).

As shown in Figure 3, plasma vitamin E (total tocopherol) concentrations after 4-week administration of

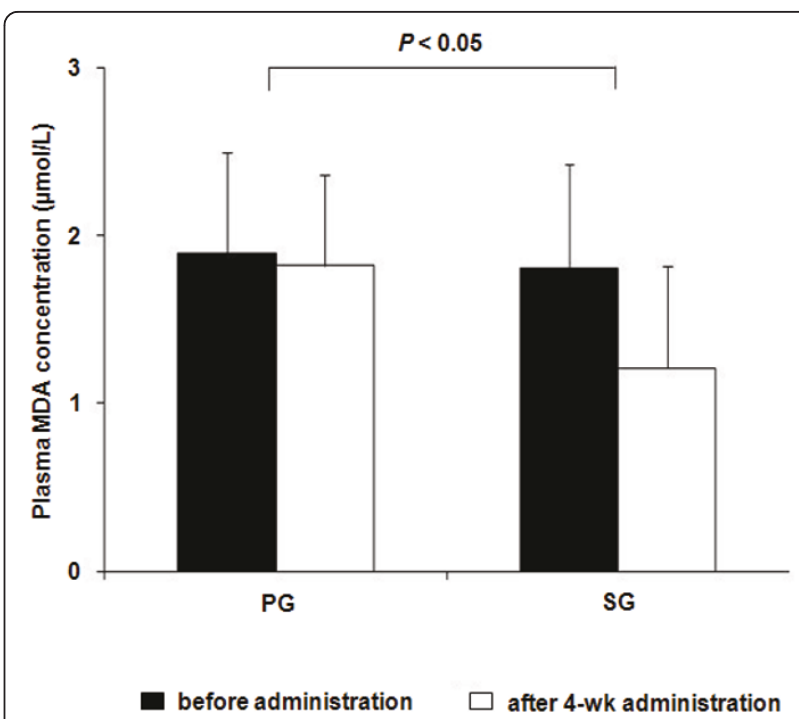

Figure 2 Plasma MDA concentrations before and after 4-week administration of black sesame meal and a placebo in subjects with prehypertension. Values are expressed as means $\pm S D$. PG, placebo group; SG, black sesame meal group; MDA, malondialdehyde.

black sesame meal were significantly increased when compared with before administration concentrations $(38.2 \pm 7.8$ vs. $29.4 \pm 6.0 \mu \mathrm{mol} / \mathrm{L}, P<0.01)$. There were no significant differences in vitamin $\mathrm{E}$ concentrations before and after 4-week administration of the placebo $(29.8 \pm 6.0$ vs. $26.5 \pm 5.5 \mu \mathrm{mol} / \mathrm{L}, P=\mathrm{NS})$. When compared with the PG group, the SG group had significantly greater plasma vitamin $\mathrm{E}$ concentrations after 4-week of

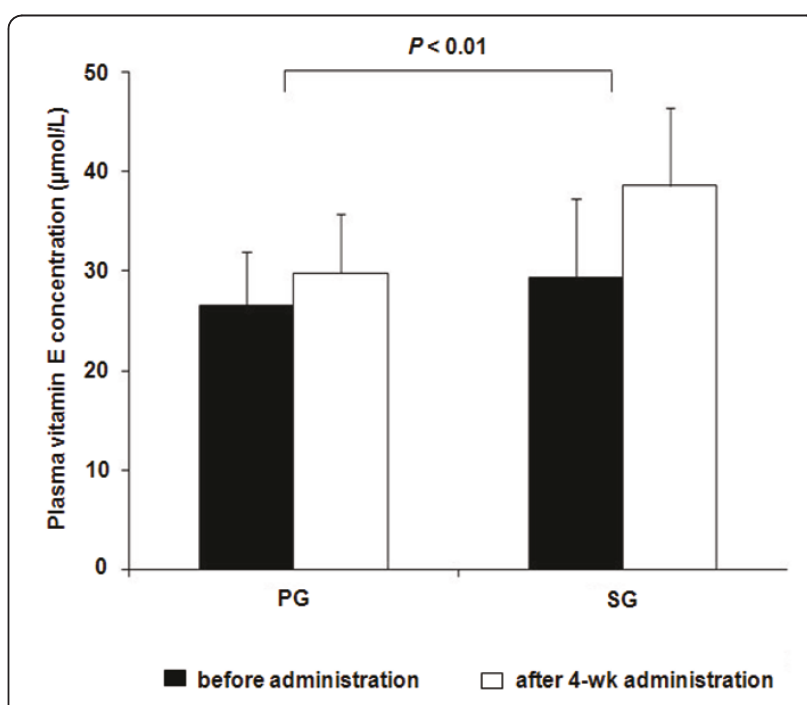

Figure 3 Plasma vitamin E concentrations before and after 4week administration of black sesame meal and a placebo in subjects with prehypertension. Values are expressed as means \pm SD. PG, placebo group; SG, black sesame meal group. 
administration with adjustment for baseline values (29.8 \pm 6.0 (PG), $38.2 \pm 7.8$ (SG) $\mu \mathrm{mol} / \mathrm{L}, P<0.01$ ).

Only in the black sesame meal group did the change in SBP tend to be positively related to the change in MDA concentration $(R=0.50, P=0.05)$, while the change in DBP was negatively related to the change in vitamin $\mathrm{E}$ concentration $(R=0.55, P<0.05)$. There were no significant correlations between changes in BP and oxidative stress indicators in the placebo group.

\section{Discussion}

This study appears to be the first to reveal the possible antihypertensive effects of black sesame meal in participants with prehypertension. The results demonstrated that after matching for age, BMI and BP, 4-week daily administration of $2.52 \mathrm{~g}$ black sesame meal caused a significant reduction in SBP, by an average of $8.2 \mathrm{mmHg}$.

Interestingly, the INTERSALT study revealed that a reduction of 2 to $3 \mathrm{mmHg}$ of SBP was associated with a $4 \%$ decrease in mortality from CVD in the USA and UK [22] and a 6.4\% decrease in mortality from cerebral vascular disease in Japan [1]. Based on these longer term studies, if the present reduction in BP with sesame meal $(8.2 \mathrm{mmHg})$ was sustained in the long term, this could reduce the risk of CVD and stroke by $16.4 \%$ and $26.2 \%$ respectively. This study shows that the ingestion of black sesame meal may have a potential effect on reduction in mortality from CVD and stroke.

Although no previous study has directly investigated the effect of black sesame meal on BP, many studies have reported the potential antihypertensive effect of sesame's contents (i.e. lignan and vitamin E) in humans and rats $[8-11,23]$. However, this is inconsistent with many other previous studies which reported different results [12-14]. Some previous studies have reported that supplementation of either alpha-tocopherol alone or mixed with gammatocopherol increased [12] or did not change [13] BP in diabetic or treated hypertensive patients [14]. This may be attributed to an interference of alpha-tocopherol and the antihypertensive drug taken by some subjects in previous studies; whereas subjects in this study were healthy and did not take any antihypertensive drug. Moreover, the dose of vitamin $\mathrm{E}$ in those previous studies may have been so high that it caused increased or unchanged effects on BP.

A possible mechanism responsible for the antihypertensive effect of black sesame meal in this study may be an improved balance between relaxing and contracting factors in the endothelium of blood vessels. In this study, black sesame meal may have enhanced the relaxing factor, resulting in improved endothelium-dependent vasorelaxation in the pre-hypertensive participants relating to oxidative stress. The antihypertensive effect of sesamin, in mildly hypertensive humans was supported by a previous study [9]. The authors reported that the ingestion of $60 \mathrm{~g}$ of sesamin per day for 4 weeks decreased SBP by an average of $3.5 \mathrm{mmHg}$, and DBP by $1.9 \mathrm{mmHg}$ [9]. Moreover, the increased plasma vitamin $\mathrm{E}$ in this study may be due to the increased vitamin $\mathrm{E}$ or the inhibition of catabolism of vitamin E. In addition, bioavailability of vitamin $\mathrm{E}$ may be increased by interactions between sesame lignan and tocopherols [24]. The accumulation of vitamin $E$ acts by detoxifying the hydroxyl and proxy radicals, leading to reduced lipid peroxidation, or by reducing excess tissue aldehydes [11]. This is supported by many previous studies, in which supplementation of either vitamin $\mathrm{E}$ or sesamin and sesamolin demonstrated that these antioxidants inhibit lipid peroxidation [3-7,25]. The antioxidant effect is likely to contribute to the decreased endothelial dysfunction from free radicals [26], resulting in an increase in the vasorelaxing factor, nitric oxide (NO) [27].

However, a mechanism that is not relevant to oxidative stress cannot be ruled out. This was supported by a study by Ward et al. (2004) which failed to show a link between oxidative stress and BP [28]. It was shown that gammatocopherol supplementation increased protein expression of nitric oxide synthase [29], which stimulates vasorelaxation. Moreover, the potential effect of vitamin E on membrane fluidity is likely to be another mechanism of antihypertension. In vitro study, vitamin $\mathrm{E}$ was shown to preserve endothelial cell (EC) migration in oxidized lowdensity lipoprotein cells (oxLDL) and restore the endothelial monolayer after injury by inhibiting changes in membrane integrity caused by oxLDL [30]. A previous study in rats demonstrated that antihypertensive rats had lower BP than normotensive rats due to reduced membrane fluidity after ingestion of vitamin E $3 \mathrm{~d} /$ week for 3 weeks [31]. These non-antioxidant properties of vitamin $\mathrm{E}$ could be important in the prevention of atherosclerosis, resulting in a reduction in BP in humans. Sesamin supplementation also induced $\mathrm{NO}$ and inhibited endothelin-1 production by EC [32]. These findings indicate an improved ability of the endothelium to relax. In addition, a recent study has shown that sesamin inhibited some CYP450 enzymes and the production of 20-hydroxyeicosatetraenoic acid (20-HETE), which might influence BP independently of any effects on oxidative stress [33]. Moreover, sesamin increased $\mathrm{Ca}^{2+}$ antagonistic vasorelaxing activity [34]. It should be emphasized in this discussion that these hypotheses are only on the basis of the decrease in MDA and increased vitamin E, because other possible mechanisms were not measured.

A limitation of this study is a lack of data on endothelium-dependent vasorelaxation determined by $\mathrm{NO}$ and other antioxidants such as vitamin C. Moreover, the potential effect of vitamin $\mathrm{E}$ on membrane fluidity and the ability of sesame lignans to inhibit 20-HETE synthesis in human renal and liver microsomes were not investigated by this study. Thus, further investigation of these 
variables explaining the mechanisms of black sesame meal on prevention of hypertension is needed. Importantly, having no discernible side effects from the ingestion of black sesame meal throughout this study implies that it may be safe as a nutritional supplement for health promotion.

\section{Conclusions}

This study suggests a beneficial effect of dietary black sesame meal on a reduction in blood pressure in prehypertensive humans. It is likely that the antihypertensive effect is due to decreased oxidative stress. Taken together with the absence of side effects and inexpensive preparation, the regular ingestion of dietary black sesame meal may be beneficial for CVD prevention in individuals with prehypertension, or even those with hypertension. A future study that investigates this advantageous effect is suggested.

\section{Acknowledgements}

We appreciate the assistance of the physical therapists at Queen Sirikit Heart Center of Northeast Thailand. We also appreciate Exercise and Sport Sciences Development and Research Group and Cardiovascular Research Group, Khon Kaen University (a grant number 511010008), Thailand for financial supports. We also would like to thank all subjects for their enthusiastic participation.

\section{Author details}

${ }^{1}$ Faculty of Physical Therapy, Mahidol University, Nakhon Pathom 73170, Thailand. ${ }^{2}$ Faculty of Pharmaceutical Sciences, Khon Kaen University, Khon Kaen 40002, Thailand. ${ }^{3}$ Department of Biochemistry, Faculty of Medicine, Khon Kaen University, Khon Kaen 40002, Thailand. ${ }^{4}$ Department of Pathology, Faculty of Medicine, Khon Kaen University, Khon Kaen 40002. Thailand. ${ }^{5}$ Department of Clinical Chemistry, Faculty of Associated Medical Sciences, Khon Kaen University, Khon Kaen 40002, Thailand. ${ }^{6}$ Department of Clinical Microscopy, Faculty of Associated Medical Sciences, Khon Kaen University, Khon Kaen 40002, Thailand. Department of Clinical Immunology, Faculty of Associated Medical Sciences, Khon Kaen University, Khon Kaen

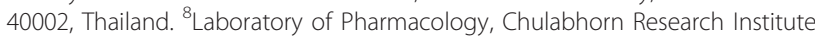
(CRI), Vibhavadee-Rangsit Highway, Laksi, Bangkok 10210, Thailand.

${ }^{9}$ Department of Physiology, Faculty of Medicine, Khon Kaen University, Khon Kaen 40002, Thailand.

\section{Authors' contributions}

JW participated in the design of the study and carried out the plasma MDA and vitamin E assay, physiological measurements and statistical analysis. NW prepared the black sesame meal. PB carried out the vitamin E assay. SS performed the medical cover. NL conceived the study, participated in its design and coordination. NR analyzed vitamin E and lignans in black sesame meal. JW and NL drafted the manuscript. NL is a member of Exercise and Sport Sciences Development and Research Group. NW, CS, NS, NK, SS and YT are members of Cardiovascular Research Group. All authors have read and approved the final manuscript.

\section{Competing interests}

The authors are applying for a patent on black sesame meal.

Received: 11 March 2011 Accepted: 9 August 2011

Published: 9 August 2011

\section{References}

1. Japanese Society of Hypertension: Japanese Society of Hypertension guidelines for the management of hypertension (JSH 2004). Hypertens Res 2006, 29(Suppl):S1-S105.
2. Dhalla NS, Temsah RM, Netticadan T: Role of oxidative stress in cardiovascular diseases. J Hypertens 2000, 18:655-673.

3. Cooney RV, Custer $\sqcup$, Okinaka L, Franke AA: Effects of dietary sesame seeds on plasma tocopherol levels. Nutr Cancer 2001, 39:66-71.

4. Ikeda S, Kagaya M, Kobayashi K, Tohyama T, Kiso Y, Higuchi N, Yamashita K: Dietary sesame lignans decrease lipid peroxidation in rats fed docosahexaenoic acid. J Nutr Sci Vitaminol (Tokyo) 2003, 49:270-276.

5. Kang MH, Naito M, Tsujihara N, Osawa T: Sesamolin inhibits lipid peroxidation in rat liver and kidney. J Nutr 1998, 128:1018-1022.

6. Nakai M, Harada M, Nakahara K, Akimoto K, Shibata H, Miki W, Kiso Y: Novel antioxidative metabolites in rat liver with ingested sesamin. J Agric Food Chem 2003, 51:1666-1670.

7. Yamashita K, lizuka Y, Imai T, Namiki M: Sesame seed and its lignans produce marked enhancement of vitamin E activity in rats fed a low alpha-tocopherol diet. Lipids 1995, 30:1019-1028.

8. Boshtam M, Rafiei M, Sadeghi K, Sarraf-Zadegan N: Vitamin E can reduce blood pressure in mild hypertensives. Int I Vitam Nutr Res 2002, 72:309-314.

9. Miyawaki T, Aono H, Toyoda-Ono Y, Maeda H, Kiso Y, Moriyama K. Antihypertensive effects of sesamin in humans. J Nutr Sci Vitaminol (Tokyo) 2009, 55:87-91.

10. Sankar D, Rao MR, Sambandam G, Pugalendi KV: Effect of sesame oil on diuretics or $\beta$-blockers in the modulation of blood pressure, anthropometry, lipid profile, and redox status. Yale J Biol Med 2006, 79:19-26.

11. Sankar D, Sambandam G, Rao MR, Pugalendi KV: Modulation of blood pressure, lipid profiles and redox status in hypertensive patients taking different edible oils. Clin Chim Acta 2005, 355:97-104.

12. Ward NC, Wu JH, Clarke MW, Puddey IB, Burke V, Croft KD, Hodgson JM The effect of vitamin $E$ on blood pressure in individuals with type 2 diabetes: a randomized, double-blind, placebo-controlled trial. J Hypertens 2007, 25:227-234.

13. Economides PA, Khaodhiar L, Caselli A, Caballero AE, Keenan H, Bursell SE, King GL, Johnstone MT, Horton RS, Veves A: The effect of vitamin E on endothelial function of micro- and macrocirculation and left ventricular function in type 1 and type 2 diabetic patients. Diabetes 2005, 54:204-211.

14. Palumbo G, Avanzini F, Alli C, Roncaglioni MC, Ronchi E, Cristofari M, Capra A, Rossi S, Nosotti L, Costantini C, Cavalera C: Effects of vitamin E on clinic and ambulatory blood pressure in treated hypertensive patients. Collaborative Group of the Primary Prevention Project (PPP) Hypertension study. Am J Hypertens 2000, 5(Pt 1):564-567.

15. Brigelius-Flohé R: Vitamin E and drug metabolism. Biochem Biophys Res Commun 2003, 305:737-740.

16. Chobanian AV, Bakris GL, Black HR, Cushman WC, Green LA, Izzo JL Jr, Jones DW, Materson BJ, Oparil S, Wright JT Jr, Roccella EJ: The Seventh Report of the Joint National Committee on Prevention, Detection, Evaluation, and Treatment of High Blood Pressure: The JNC 7 Report. JAMA 2003, 289:2560-2571.

17. Kontush A, Spranger T, Reich A, Baum K, Beisiegel U: Lipophilic antioxidants in blood plasma as markers of atherosclerosis: the role of alpha-carotene and gamma-tocopherol. Atherosclerosis 1999, 144:117-122.

18. Institute of Medicine, Food and Nutrition Board: Dietary Reference Intakes for Vitamin C, Vitamin E, Selenium, and Carotenoids. Washington, DC: National Academy Press; 2000.

19. Rangkadilok N, Pholphana N, Mahidol C, Wongyai W, Saengsooksree K, Nookabkaew S, Satayavivad J: Variation of sesamin, sesamolin and tocopherols in sesame (Sesamum indicum L.) seeds and oil products in Thailand. Food Chemistry 2010, 122:724-730.

20. Draper HH, Squires EJ, Mahmoodi H, Wu J, Agarwal S, Hadley M: A comparative evaluation of thiobarbituric acid methods for the determination of malondialdehyde in biological materials. Free Radic Biol Med 1993, 15:353-363.

21. Thurnham DI, Smith E, Flora PS: Concurrent liquid-chromatographic assay of retinol, alpha-tocopherol, beta-carotene, alpha-carotene, lycopene, and beta-cryptoxanthin in plasma, with tocopherol acetate as internal standard. Clin Chem 1988, 34:377-381.

22. Stamler J, Rose G, Stamler R, Elliott P, Dyer A, Marmot M: INTERSALT study finding: public health and medical care implications. Hypertension 1989, 14:570-577. 
23. Noguchi T, Ikeda K, Sasaki Y, Yamamoto J, Yamori Y: Effects of vitamin E and sesamin on hypertension and cerebral thrombogenesis in strokeprone spontaneously hypertensive rats. Clin Exp Pharmacol Physiol 2004, 31(Suppl 2):24-26.

24. Kamal-Eldin A, Frank J, Razdan A, Tengblad S, Basu S, Vessby B: Effects of dietary phenolic compounds on tocopherol, cholesterol, and fatty acids in rats. Lipids 2000, 35:427-435.

25. Ikeda S, Abe C, Uchida T, Ichikawa T, Horio F, Yamashita K: Dietary sesame seed and its lignan increase both ascorbic acid concentration in some tissues and urinary excretion by stimulating biosynthesis in rats. J Nutr Sci Vitaminol (Tokyo) 2007, 53:383-392.

26. Ito $H$, Torii M, Suzuki T: Comparative study on free radical injury in the endothelium of SHR and WKY aorta. Clin Exp Pharmacol Physiol 1995, 22(Suppl 2):157-159.

27. Thomas SR, Chen K, Keaney JF Jr: Oxidative stress and endothelial nitric oxide bioactivity. Antioxid Redox Signal 2003, 5:181-194.

28. Ward NC, Hodgson JM, Puddey IB, Mori TA, Beilin LJ, Croft KD: Oxidative stress in human hypertension: association with antihypertensive treatment, gender, nutrition, and lifestyle. Free Radical Biol Med 2004, 36:226-232.

29. Li D, Saldeen T, Romeo F, Mehta JL: Relative effects of alpha- and gamma-tocopherol on low-density lipoprotein oxidation and superoxide dismutase and nitric oxide synthase activity and protein expression in rats. J Cardiovasc Pharmacol Ther 1999, 4:219-226.

30. van Aalst JA, Burmeister W, Fox PL, Graham LM: Alpha-tocopherol preserves endothelial cell migration in the presence of cell-oxidized lowdensity lipoprotein by inhibiting changes in cell membrane fluidity. $J$ Vasc Surg 2004, 39:229-237.

31. Pezeshk A, Derick Dalhouse A: Vitamin E, membrane fluidity, and blood pressure in hypertensive and normotensive rats. Life Sci 2000 67:1881-1889.

32. Lee CC, Chen PR, Lin S, Tsai SC, Wang BW, Chen WW, Tsai CE, Shyu KG: Sesamin induces nitric oxide and decreases endothelin-1 production in HUVECs: possible implications for its antihypertensive effect. J Hypertens 2004, 22:2329-2338.

33. Wu JH, Hodgson JM, Clarke MW, Indrawan AP, Barden AE, Puddey IB, Croft KD: Inhibition of 20-hydroxyeicosatetraenoic acid synthesis using specific plant lignans: in vitro and human studies. Hypertension 2009, 54:1151-1158.

34. Nakano D, Kwak CJ, Fujii K, Ikemura K, Satake A, Ohkita M, Takaoka M, Ono Y, Nakai M, Tomimori N, Kiso Y, Matsumura Y: Sesamin metabolites induce an endothelial nitric oxide-dependent vasorelaxation through their antioxidative property-independent mechanisms: possible involvement of the metabolites in the antihypertensive effect of sesamin. J Pharmacol Exp Ther 2006, 318:328-335.

doi:10.1186/1475-2891-10-82

Cite this article as: Wichitsranoi et al: Antihypertensive and antioxidant effects of dietary black sesame meal in pre-hypertensive humans. Nutrition Journal 2011 10:82.

\section{Submit your next manuscript to BioMed Central and take full advantage of:}

- Convenient online submission

- Thorough peer review

- No space constraints or color figure charges

- Immediate publication on acceptance

- Inclusion in PubMed, CAS, Scopus and Google Scholar

- Research which is freely available for redistribution

Submit your manuscript at www.biomedcentral.com/submit
Biomed Central 